УДК 74.3

\title{
Глава 12.
}

ПЕДАГОГИЧЕСКАЯ ТЕХНОЛОГИЯ ОБУЧЕНИЯ

СПЕЦИАЛИСТОВ-ДЕФЕКТОЛОГОВ ЧТЕНИЮ И ПИСЬМУ

ПО СИСТЕМЕ Л. БРАЙЛЯ

\section{Карандаева Татьяна Аркадьевна} канд. пед. наук доцент кафедры специальной педагогики и психологии ФГБОУ ВПО «Марийский государственный университет»

Аннотация: данная работа посвящена одному из важнейших направлений деятельности в подготовке дефектологов - обучению чтению и письму по системе Брайля и нацелена на повышение качества подготовки специалистов коррекционно-образовательных учреждений для лиц с глубокими нарушениями зрения. В ней приводятся теоретические и практические сведения об организации и содержании обучения чтению и письму по системе Брайля, а также авторская технология, оптимизирующая данный процесс.

Ключевые слова: рельефно-точечный шрифт, шеститочие Брайля, прибор для письма, грифель, правила письма.

\section{PEDAGOGICAL TECHNOLOGY OF TEACHING FUTURE SPEECH PATHOLOGISTS TO READ AND WRITE ACCORDING TO THE L. BRAILLE SYSTEM}

Karandaeva Tatiana Arkadyevna 
Abstract: this work is devoted to one of the most important areas of activity in the training of speech pathologists - teaching reading and writing in the Braille system and is aimed at improving the quality of training specialists for correctional and educational institutions for people with profound visual impairments. It provides theoretical and practical information about the organization and content of teaching reading and writing in Braille, as well as the author's technology that optimizes this process.

Key words: relief-dot font, Braille hexadecimal, writing device, pencil, rules for writing.

\section{Введение}

В настоящее время одним из важнейших концептуальных положений модернизации образования провозглашается компетентностный подход.

Повышение уровня профессиональных компетенций в системе специального образования требует преобразования содержания и средств подготовки специалистов-дефектологов, в частности, специалистов тифлопедагогов. Для будущего тифлопедагога знание системы рельефноточечного письма Л. Брайля является одним из непременных условий работы с детьми с глубокими нарушениями зрения.

Bce большее значение в специальном образовании придается компьютерной грамотности детей, однако, чтение и письмо по системе Брайля было и остается обязательным и необходимым условием для качественного обучения, развития и социализации детей, имеющих глубокие нарушения зрения [4].

О необходимости изучения системы Л. Брайля для дошкольников с глубокими нарушениями зрения писали такие тифлологи, как В.3. Денискина, В.3 Кантор, Н.Н. Рогушин Г.В. Никулина, Л.И. Солнцева и другие.

Традиционный способ письма рельефно-точечным шрифтом остается 
широко распространенным и, в то же время, сложным, но без него невозможно обучение грамоте и получение образования, поэтому потребность в подготовленных специалистах, владеющих системой Л. Брайля достаточно высока, особенно в условиях инклюзивного образования.

В данной работе предложена педагогическая технология подготовки специалистов к обучению лиц с глубокими нарушениями зрения чтению и письму по системе Л. Брайля. Актуальность такой работы обусловлена тем, что в условиях специального образовании, а еще более в условиях инклюзивного образования все чаще возникает потребность в хорошо подготовленных специалистах, владеющих рельефно-точечным шрифтом Л. Брайля. Также никто не может помочь родителям, имеющим детей с глубокими нарушениями зрения, в дошкольных образовательных учреждениях в освоении системы и подготовке детей к обучению чтению и письму по системе Брайля.

Теория и практика обучения лиц с глубокими нарушениями зрения показывает, что, несмотря на все более высокий уровень компьютерной грамотности детей, чтение и письмо по системе Брайля было и остается обязательным и необходимым условием для качественного обучения, развития и социализации детей, имеющих глубокие нарушения зрения. Без этого невозможно обучение грамоте и получение образования. Традиционный способ письма рельефно-точечным шрифтом остается широко распространенным и, в то же время, сложным, поэтому потребность в подготовленных специалистах дефектологах, владеющих системой Л Брайля достаточно высока, особенно в условиях инклюзивного образования.

В основу разработки авторской технологии обучения специалистов дефектологов чтению и письму по системе Л. Брайля был положен практикоориентированный подход, позволяющий педагогу не только проанализировать опыт других специалистов, занимающихся этой проблемой, но и собственный двадцатилетний опыт преподавания курса по обучению студентов - 
дефектологов рельефно-точечному шрифту Л. Брайля.

Система обучения будущих дефектологов, имеющих зрение, должна отличаться от системы обучения незрячих, как детей, так и взрослых. Взрослым зрячим специалистам значительно быстрее удается запомнить все буквы, цифры и знаки, если они используют азбуку Л. Брайля, созданную для латинского алфавита, которая содержит более логичную и методически обоснованную последовательность изучения букв. Этот способ изучения системы Брайля наиболее удобен для родителей, имеющих детей с глубокими нарушениями зрения и для педагогов, не имеющих дефектологического образования, работающих с такими детьми в условиях инклюзии.

Опытно-исследовательская работа позволила определиться со структурой и составом необходимого материала для разработки программы обучения специалистов - дефектологов чтению и письму по системе Брайля.

\section{1 Приборы для письма}

Для обучения письму, обучающимся необходимо сначала познакомиться с письменными принадлежностями, такими, как прибор и тетрадь для письма по системе Брайля и грифель.

Как правило, стандартный письменный прибор изготавливается из пластмассы или металла и состоит из двух прямоугольных пластин, соединенных подвижно шарниром. Верхняя пластина прибора (прямоугольная крышка) представляет собой решетку из прямоугольных окошек. Нижняя пластина прибора разделена на 18 строк по 24 клеточки с шестью углублениями, разделенными сплошными перегородками в каждой клеточке. Таким образом, на нем можно записать 432 знака вместе с пробелами. Размер клетки - 7,25 х 4,65 мм. В каждой клетке имеется 6 углублений для удобства прокалывания бумаги. Вверху и внизу на нижней пластине имеются по 2 фиксатора (штифты), а на верхней пластине им соответствуют отверстия для 
закрепления бумаги [3].

Обратная сторона письменного прибора представляет собой гладкую пластину. Специальная бумага закладывается в прибор, выравнивается по верхнему и левому краям прибора крепится штифтами при помощи нажатия на верхнюю крышку прибора над теми местами, где находятся штифты (Рис. 1).
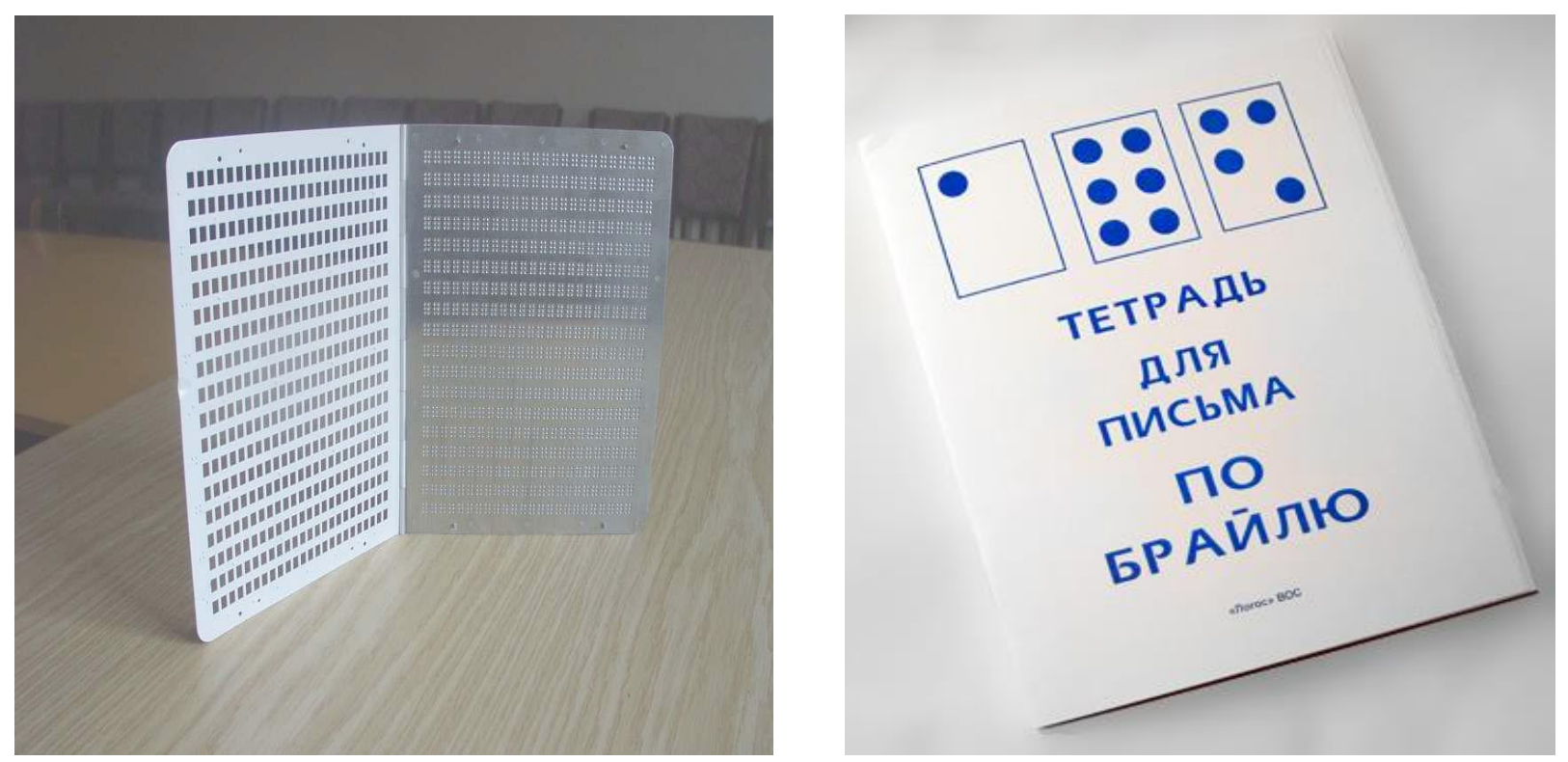

Рис. 1. Стандартный прибор Брайля (18 строк) тетрадь для письма

Для письма используется специальная, матовая, перфокарточная бумага в листах (формат 390х245 мм.) сшитая в тетрадь (Рис. 1). Бумага имеет достаточную толщину, плотность и пластичность, чтобы при нажатии стержнем грифеля на бумагу она, деформируясь, вытягивалась, принимая форму полусферической поверхности. С изнаночной стороны листа осязательно она воспринимается как точка, высота которой составляет 0,5 мм. Письмо осуществляется специальным прибором - грифелем. 


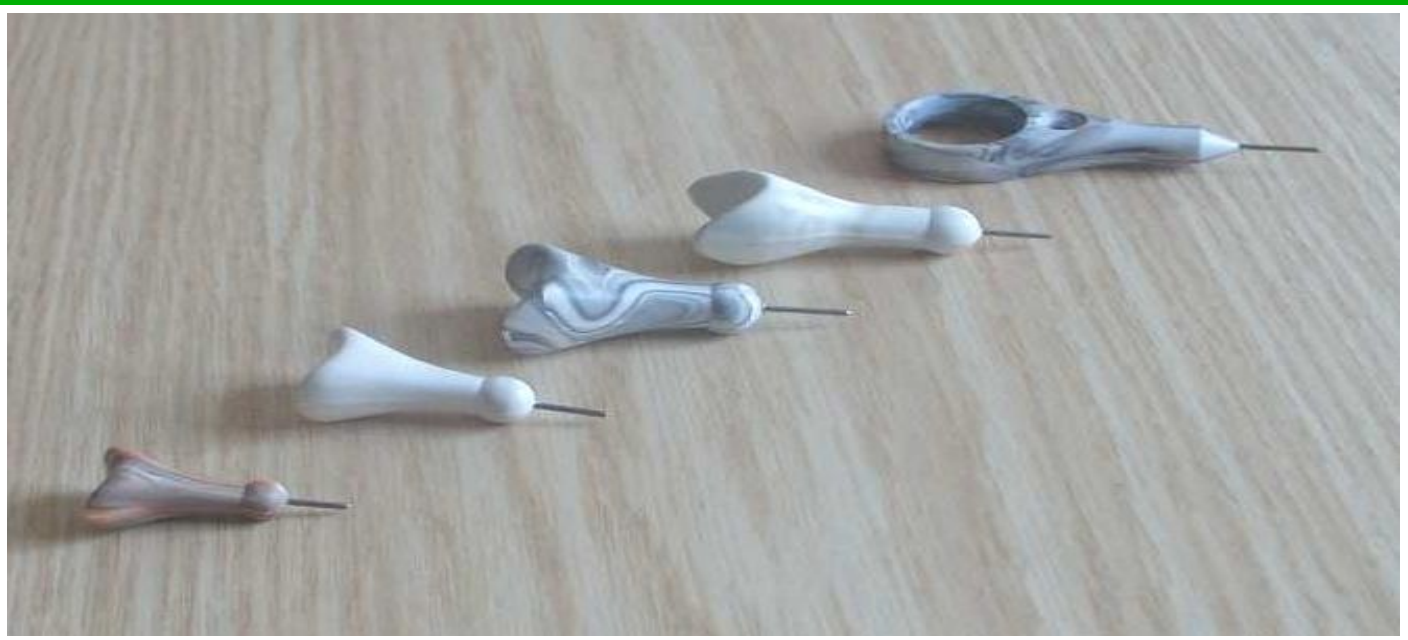

\section{Рис. 2. Грифели для письма по Брайлю}

Грифель представляет собой шильце с пластмассовой ручкой и вставленным металлическим стержнем с тупым концом, пластмассовая ручка которого имеет выемку в верхней части (Рис. 2).

Для детей и взрослых существует несколько разновидностей грифелей

Важно отметить, что «грифель следует держать в правой руке, обхватывая его сверху указательным пальцем через выемку; большой и средний пальцы должны прижимать грифель с боковых сторон, а безымянный палец и мизинец должны быть подогнуты. Грифелем можно не только писать, но и читать написанный текст, не вынимая листа из прибора.

Письмо производится правой рукой путем прокалывания бумаги легким нажимом грифеля сверху. Грифель должен быть перпендикулярен плоскости прибора. Все пальцы левой руки двигаются по строке справа налево, а боковая часть указательного пальца находится в той клетке, в которой производится накалывание точек и касается кончика грифеля. Накалывание точек осуществляется движением кисти правой руки. При этом, накалывание точек производится в определенном порядке: сначала накалывают точки с правого края сверху вниз, а затем, с левого края сверху вниз. Левая рука движется всегда впереди правой руки, служит ориентиром и контролирует письмо» $[3$, c. 16]. 
Чтение у слепых людей осуществляется с помощью осязания указательными пальцами обеих рук, в дальнейшем в этом процессе принимают участие и другие пальцы.

Л.И. Солнцева отмечала, что формирование образа Брайлевской буквы предполагает системность, комплексность образов, включение в его структуру представлений разных модальностей и разного уровня обобщенности. Это относится и к формированию сенсорного образа буквы и визуального образа [10].

В.3. Денискина, Н.С. Костючек предлагают использовать в пропедевтических целях на начальном этапе обучения по системе Л. Брайля «Прибор прямого чтения» и прибор «Брайлевское шеститочие».

Наиболее современным и часто используемым является прибор «Кубикбуква» (Рис. 3), он «предназначен для обучения незрячих людей системе Брайля. С помощью трёх подвижных элементов, на которых размещены рельефные точки, можно составить букву или знак по системе Брайля. На каждой из четырех граней этих элементов, как в «домино», имеются изображения: «пусто - пусто», «пусто - точка», «точка - пусто», «точка - точка» $[3$, c.17].

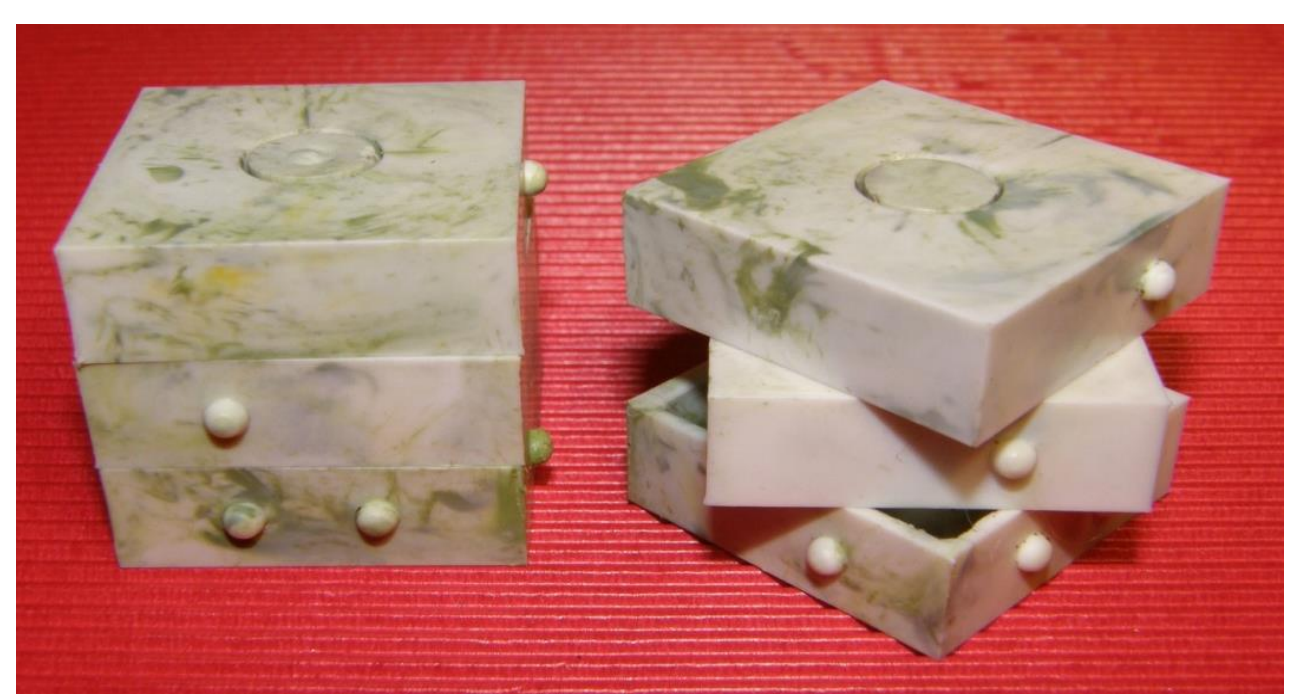

Рис. 3. Прибор «Кубик-буква» 
Прибор «Кубик буква» используется обучающимися на начальном этапе обучения для формирования образа буквы и с целью наиболее быстрого запоминания.

\section{2 Правила записи знаков рельефно-точечного шрифта Л. Брайля}

Система чтения и письма Л. Брайля представляет собой рельефноточечный шрифт, в котором каждый символ является комбинацией точек, расположенных в определенном порядке в пределах шеститочия (шести точек), расположенных в 2 столбца, по 3 точки в каждом. Все точки имеют определенный порядковый номер.

Точки имеют цифровые обозначения. В левом вертикальном ряду они обозначены сверху вниз цифрами 1, 2, 3; в правом - 4, 5, 6.

Нумерация точек при чтении идёт слева - направо и сверху вниз по столбцам (Рис. 4). При письме, - наоборот справа - налево и сверху - вниз.

Письмо производится справа - налево, а чтение слева - направо.

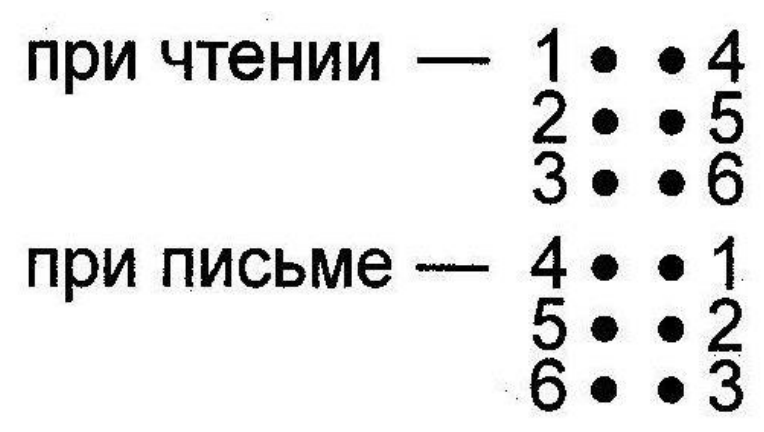

Рис. 4. Нумерация точек при чтении и при письме

Создавая алфавит, Л. Брайль выбирал простейшие из возможных комбинаций. «Из комбинаций верхних четырех точек он создал первые десять букв французского алфавита. Эти буквы Брайль назвал основными. Путем прибавления к ним третьей точки он создал вторую серию букв. Присоединением к основным буквам третьей и шестой точек были созданы 
остальные буквы алфавита. Путем перемещения точек на один ряд ниже Брайль образовал из основных букв знаки препинания. Одна, вторая точка шеститочия, обозначала запятую, вторая и пятая точки - двоеточие, вторая и третья точку с запятой и т.д. Все цифры соответствуют первым десяти буквам латинского алфавита или буквам первой строки" [3, с,.22-23].

Л. Брайль расположил все символы в таблицу, которая состоит из 7 строк, 5 из них содержат по 10 символов, а в двух последних, соответственно по 6 и 7 символов.

В первой строке таблицы Л. Брайля расположены первые 10 букв латинского алфавита. Эти буквы соответствуют также цифрам: 1, 2, 3, 4, 5, 6, 7 , $8,9,0$, если впереди их обозначений поставить цифровой знак (3456). Первая строка не содержит точек 3 и 6 , то есть все точки располагаются в двух верхних строчках.

Во второй строке расположены следующие 10 букв латинского алфавита. При этом к цифрам или буквам первой строки добавляется точка 3.

В третьей строке к каждому знаку первой строки добавлены точки 3 и 6.

В четвертой строке к знакам первой строки добавляется только точка 6.

В пятой строке все знаки первой строки снижены на одну горизонтальную линию, то есть, расположены во второй и третьей строчках.

Шестая строка (первая дополнительная строка) состоит из шести знаков и образована из комбинаций точек $3,4,5,6$.

Л. Брайль для обозначения букв французского алфавита взял первые четыре строки своей системы. В пятой строке содержатся знаки препинания, круглые скобки, кавычки, звездочки. В шестой строке (первой дополнительной) содержатся знаки математических действий.

Признаки больших букв каждого алфавита образуются из признаков малых букв того же алфавита, путем добавления к ним точки 4 с соблюдением следующих правил. 
1. Признак алфавита ставится:

- перед отдельной буквой, стоящей в литературном тексте;

- перед первой буквой математического выражения и перед каждой частью записи равенства или неравенства, и сохраняет свое действие для всех последующих букв данной записи вплоть до появления другого признака алфавита в математической записи или литературном тексте;

- при смене алфавита внутри литературного текста или математической записи;

- перед буквами первой строки, которые изображаются с помощью тех же комбинаций точек, что и цифры, если эти буквы непосредственно следуют за числом, записанных цифрами, стоящими в верхней части клетки.

2. Все символы признаков малых и больших букв различных алфавитов ставятся непосредственно перед буквой, а перед ними пропускается клетка.

3. Признак алфавита всегда ставится перед признаком шрифта.

Однако при печатании книг рельефно-точечным шрифтом в целях экономии площади письма в учебной и художественной литературе не всегда ставится знак большой буквы, то есть обязательное требование употребление знака заглавной буквы в начале предложения является излишним.

4. Признак малой буквы русского алфавита - точка 5. Признак большой буквы русского алфавита точки 4 и 5 (45). Они пишутся в одной клетке.

В России при письме по-русски признак малой буквы не ставится.

5. Признак малой буквы латинского алфавита - точка 6. Признак большой буквы латинского алфавита точки 4 и 6 (46). Признак малой буквы греческого алфавита - точки 5 и 6 (56). Признак большой буквы греческого алфавита точки 4, 5 и 6 (456).

Правила математической записи.

1. Математическая запись вместе со следующим за ней знаком препинания отделяется от литературного текста с обеих сторон пустой клеткой. 
2. В математической записи перед отдельно стоящей цифрой или числом ставится цифровой знак (3456).

3. Перед знаками, обозначающими арифметическое действие, равенство пропускается клетка, а после знаков клетка не пропускается, исключение составляет знак алгебраического умножения (3), перед ним клетка не пропускается.

\section{3 Опытно-экспериментальная работа по обучению специалистов -} дефектологов рельефно-точечному шрифту Л. Брайля

В результате обучения письму и чтению по системе Л. Брайля» обучающиеся должны:

- знать основы построения рельефно - точечной системы Л. Брайля, устройство письменного прибора и грифеля;

- уметь записывать рельефно-точечным шрифтом литературный текст и математические выражения, уверенно читать литературные тексты и математические выражения, изготавливать дидактические карточки с литературным и математическим содержанием;

- владеть способностью осуществлять коррекционно-образовательный процесс по обучению чтению и письму по системе Л. Брайля с учетом возрастных особенностей и индивидуальных образовательных потребностей лиц с глубокими нарушениями зрения.

Программа обучения чтению и письму по системе Брайля, обычно, содержит 4 раздела.

Первый раздел раскрывает основные исторические сведения о системе рельефной письменности для слепых, знакомит с историей возникновения системы Л. Брайля, с письменными принадлежностями, которыми пользуются слепые (прибор для письма, грифель, бумага).

«Будущим дефектологам необходимо овладеть следующими навыками: 
- вкладывать бумагу между пластинами прибора и закреплять с помощью четырех штифтов, имеющихся на верхнем и нижнем краях прибора, выравнивая ее по левому и верхнему краям прибора;

- правильно держать грифель; писать буквы и знаки с таким нажимом, чтобы точки были достаточно рельефными; уметь проверять грифелем написанное, не вынимая бумагу из прибора» [3, с. 20-21].

Второй раздел посвящен изучению принципов построения системы Л. Брайля для латинского алфавита (Рис. 5) и, адаптированной А. И. Скребицким, системы для русского алфавита (Рис. 6).

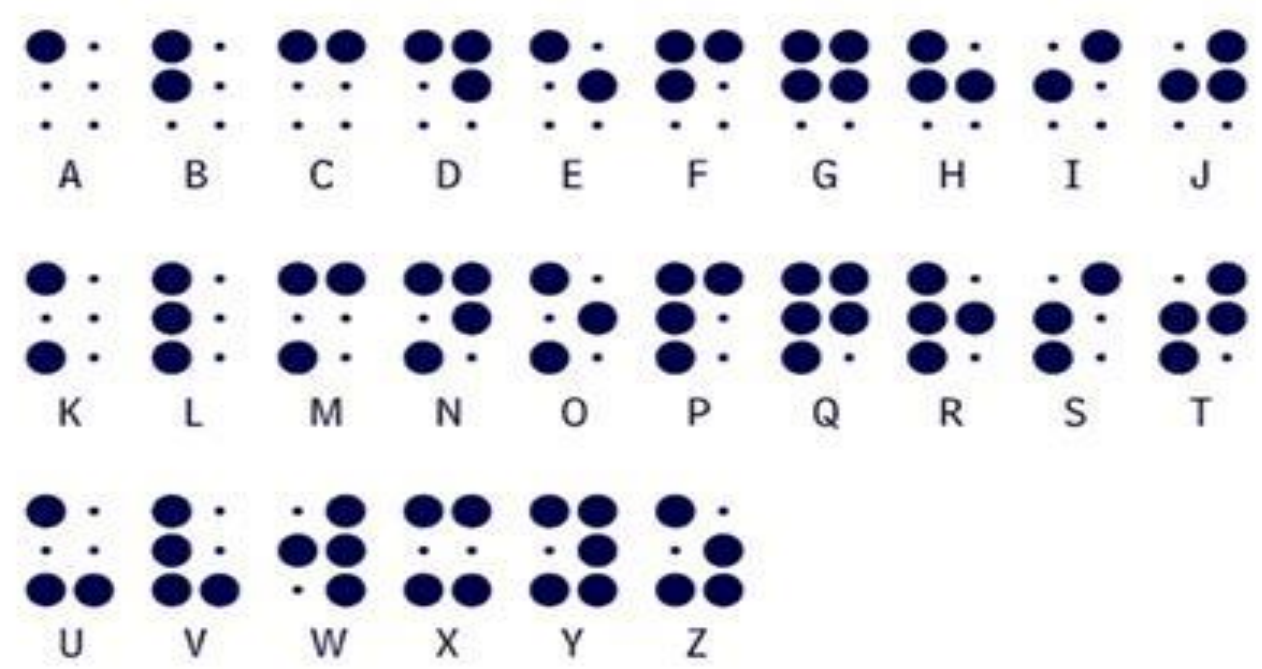

Рис. 5. Ключ к коду Л. Брайля с использованием латинского алфавита

Второй раздел посвящен изучению принципов построения системы Л. Брайля для латинского алфавита (Рис. 5) и, адаптированной А.И. Скребицким, системы для русского алфавита (Рис. 6). 


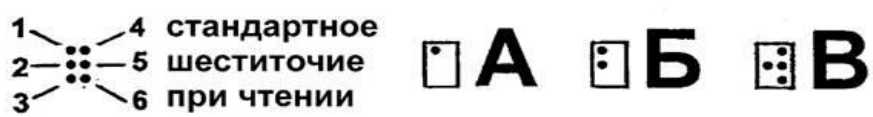 \\ 因厂

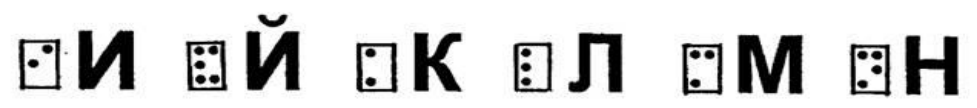 \\ 国

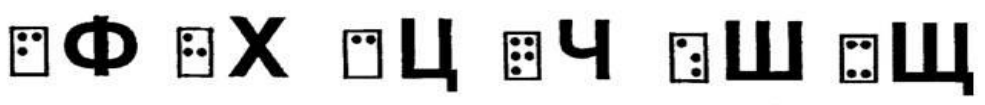

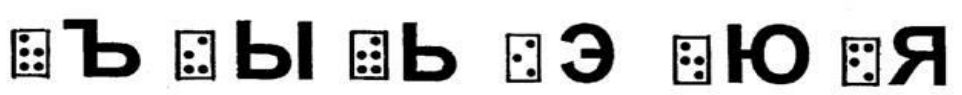

Рис. 6. Знаки рельефно-точечного шрифта, используемые в России (для русского алфавита)

Третий раздел включает в себя изучение букв, цифр, знаков препинания и знаков математических действий.

Четвертый раздел посвящен правилам для письма. «Письмо по системе Л. Брайля осуществляется не только по правилам грамматики, оно использует и свои, специфические правила. Например, необходимо знать, что цифра в системе Л. Брайля - двухзнаковый объект, неотъемлемой частью которого является цифровой знак, предшествующий цифре» [1; с.26].

Проанализировав опыт тифлопедагогов обучения письму и чтению по системе Л. Брайля и собственный двадцатилетний опыт обучения студентов дефектологов, мы предприняли попытку провести экспериментальное исследование, направленное на выявление ряда трудностей, с которыми сталкиваются обучающиеся, и на определение условий, при которых обучение студентов - дефектологов чтению и письму будет более эффективным. Были выбраны 2 группы студентов по 9 человек. Группа бакалавров (экспериментальная) и группа магистров (контрольная). 
В данной работе мы не рассматриваем огромный перечень тех трудностей, с которыми сталкиваются при обучении чтению и письму по системе Л. Брайля слепые дети и поздно ослепшие люди, речь шла только о тех трудностях, которые имели место при обучении зрячих студентов дефектологов:

- в системе Л. Брайля используется латинский алфавит, поэтому, когда обучающиеся впервые видели азбуку Брайля для русского алфавита, им очень сложно было уловить определенные закономерности в запоминании букв;

- очень часто, начиная производить первые записи рельефно-точечным шрифтом обучающиеся, по привычке, писали слева направо. Важно запомнить, что пишут - справа налево, а читают - слева направо;

- у обучающихся возникали трудности, в запоминании, написании и чтении симметричных или зеркальных пар знаков, допуская инверсии знаков в таких парах, как: И-Е, Н-Я, 3-Ы, Д-Ф, Ж-Х, Ш-С, О-Э, Р-В, Ю-Т, Ъ-Ь, 4-6, 5-9, 8-0 и других.

- обучающиеся забывали пропускать клетку между словами, особенно, когда последняя буква в слове не содержала точек 4, 5, 6 .

- затруднения возникали в соблюдении правил переноса в записи литературного текста и математических выражений;

- обучающиеся могли перепутать знаки препинания и знаки математических выражений;

- не умели находить и исправлять ошибки.

Тифлопедагоги М.И. Земцова, Н.С. Костючек и другие выделяют такие трудности письма рельефно-точечным шрифтом: «графические ошибки, которые связаны с техническими трудностями рельефного письма, своеобразно выражаются в переколах (реже недоколах) букв» [5, с. 309]. 


\section{4 Организация и содержание экспериментального обучения} студентов - дефектологов чтению и письму по системе Л. Брайля

Мы предположили, что разработанная технология обучения студентов дефектологов чтению и письму по системе Л. Брайля с использованием специальных приемов и условий обучения будет способствовать эффективности обучения и обеспечит рост профессиональной подготовленности.

Обучение будущих дефектологов контрольной и экспериментальной групп начиналось с изучения истории рельефной письменности для слепых. Они познакомились с элементами построения шрифтов В. Гаюи, У. Муна, И.В. Клейна, Ш. Барбье, Л. Брайля.

Студенты познакомились также с письменными принадлежностями, которыми пользуются слепые (прибор для письма по системе Л.Брайля, грифель, бумага), научились правильно закреплять в приборе тетрадный лист, пользоваться ориентиром строк справа на восемнадцати строчном приборе, познакомились с различными видами грифелей для письма и научились правильно держать грифель.

Многолетний опыт работы со студентами и учащимися школы слепых, начинающими изучать шрифт Брайля в старших классах, показал, что такой целостный подход к обучению, раскрывает всю сущность и закономерности этой системы. Изучение букв мы начали с азбуки не на русском, а на латинском языке. С латинскими буквами мы все знакомятся при изучении математики в пятом классе, поэтому студентам достаточно было только повторить их. В первом разделе программы изучался один и тот же материал обеими группами.

При изучении второго раздела, обучающиеся познакомились с принципами построения системы Л. Брайля для латинского алфавита и, адаптированной А. И. Скребицким, системы для русского алфавита. 
Различие приемов обучения заключалось в следующем.

Обучающиеся контрольной группы, познакомившись с таблицей символов Л. Брайля, получили таблицы символов для русского алфавита (таблицу для чтения) (Рис. 6). Обучающиеся экспериментальной группы изучали «ключ» к коду Л. Брайля через латинский алфавит и начали изучение с цифр, получив таблицу символов адаптированную для русского алфавита (Рис.7).

\begin{tabular}{|c|c|c|c|c|c|c|c|c|c|c|}
\hline 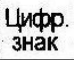 & 1 & 2 & 3 & 4 & 5 & 6 & 7 & 8 & 9 & 0 \\
\hline$: \bullet$ & $\because$ & $\because:$ & $\because:$ & $\because:$ & $\because:$ & $:$ & $\because:$ & $: \bullet$ & $:$ & $:$ \\
\hline & $\begin{array}{l}A \\
\bullet \\
\bullet\end{array}$ & G & Ц & Д & $\begin{array}{l}E \\
\vdots \\
\bullet\end{array}$ & $\begin{array}{l}\Phi \\
\bullet\end{array}$ & $\begin{array}{l}\Gamma \\
: \bullet \\
\bullet \bullet\end{array}$ & $\begin{array}{r}X \\
: \\
:\end{array}$ & $\begin{array}{l}\text { U } \\
: \\
:\end{array}$ & \% \\
\hline & $\begin{array}{l}\mathrm{K} \\
\bullet \\
\bullet\end{array}$ & $\begin{array}{l}\text { Л } \\
\vdots \\
:\end{array}$ & $\begin{array}{l}M \\
\vdots \\
\bullet\end{array}$ & $\mathrm{H}$ & $\begin{array}{l}0 \\
\bullet \\
\bullet\end{array}$ & $\begin{array}{l}\Pi \\
\bullet: \\
\bullet\end{array}$ & $\begin{array}{r}4 \\
: \\
:\end{array}$ & $\begin{array}{l}P \\
: \\
\bullet\end{array}$ & $\begin{array}{l}C \\
:\end{array}$ & T \\
\hline & $\begin{array}{l}\mathrm{y} \\
\bullet: \\
\bullet\end{array}$ & & щ & & $\begin{array}{l}3 \\
- \\
-\end{array}$ & $\check{U}$ & 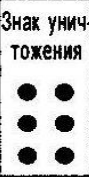 & $\begin{array}{l}\mathrm{b} \\
:\end{array}$ & bl & b \\
\hline & $\ddot{E}$ & & & & 山 & Я & & $\begin{array}{l}10 \\
:\end{array}$ & 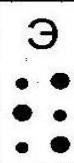 & B \\
\hline
\end{tabular}

Рис. 7. «Ключ» к коду Л. Брайля для русского алфавита

Если перед каждой из 10 основных букв алфавита (букв первой строки) ставился специальный цифровой знак (3456), в этом случае первая точка шеститочия означала не букву «а», а единицу, вторая точка — не букву «б», а цифру 2 и т. д. Таким образом, мы получили 10 цифр.

Представляется наиболее удобным начинать изучение не с букв, а с цифр, поскольку вся таблица содержит 10 знаков в каждой строке (цифр тоже 10), поэтому, переходя от строки к строке, зная закономерности их построения, значительно легче запоминать буквы, построчно увязывая их с цифрами (Рис. 8). 


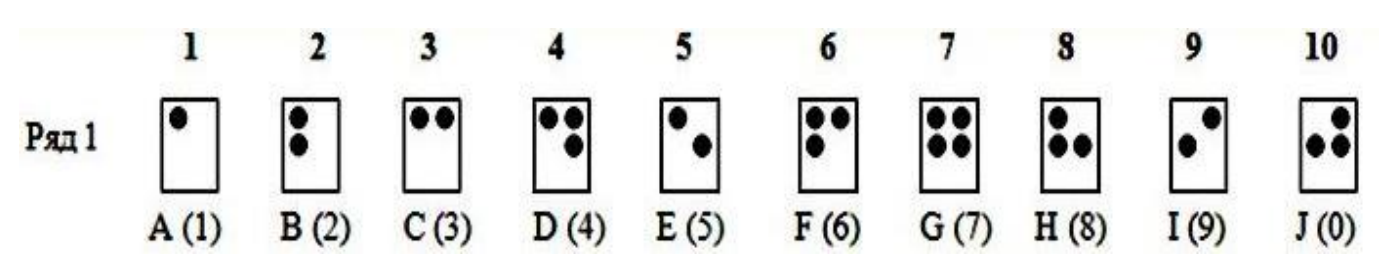

Рис. 8. Обозначение цифр и букв первой строки

Изучение букв в контрольной группе проходило в соответствии с азбукой русского алфавита и в том порядке, как они изучаются в начальной школе по букварю и методическим разработкам М. Б. Потешиной и В. К. Рогушина [7].

Изучение букв в экспериментальной группе началось не в том порядке, в котором они расположены в русском алфавите, а в соответствии с первыми буквами латинского алфавита (Рис. 8).

Зная, как записываются цифры, легко установить их соответствие с первыми десятью буквами (а, б, ц, д, е, ф, г, х, и, ж).

На первом же практическом занятии студенты экспериментальной группы запомнили, как пишутся все 10 цифр и легко писали многозначные числа. Затем научились писать 10 букв первой строки и писали слоги и слова, содержащие данные буквы, пропуская между ними пустую клетку, сами придумывали слова: да, еда, беда, цех, ах, бег, жди, беж, бац, гид, жаба, фа и другие слова.

Вторая строка содержит такие же точки, что и цифры или буквы первой строки, но к ним добавляется третья точка (к, л, м, н, о, п, ч, p, с, т).

После написания отдельных букв и слогов можно написать такие слова, как: рост, нора, фагот, слон, дом, холм, сок, сорока, корона, много. Знание двадцати букв позволяет нам записывать предложения: Дом как холм. Дима мало спал. Акула ела ананас и банан.

Изучив буквы третьей строки, образованной прибавлением к цифрам или буквам первой строки третьей и шестой точек (у, щ, з, й, ы, ъ, ь), можно писать простые предложения, например: Гол как сокол. Дело сделано. Комар носа не 240 
подточит. Дом на холме. Чистое небо. Дракон сидел на горе. Банан очень сладок. Мама мыла раму. А роза упала на лапу Азора [3, с. 93 - 94].

После изучения всех букв можно писать любые предложения, не содержащие знаков препинания.

Пятая строка таблицы строится путем снижения точек первой строки на вторую и третью горизонтальные линии шеститочия. Здесь очень важно объяснить: если знак не содержит верхних точек (1 и 4), то этот знак не может быть буквой, это либо знак препинания, либо знак математического действия. (Рис. 9). Если в знаке нет нижних точек (3 и 6), то он отображает буквы первой строки или цифры, но они должны быть записаны с цифровым знаком.

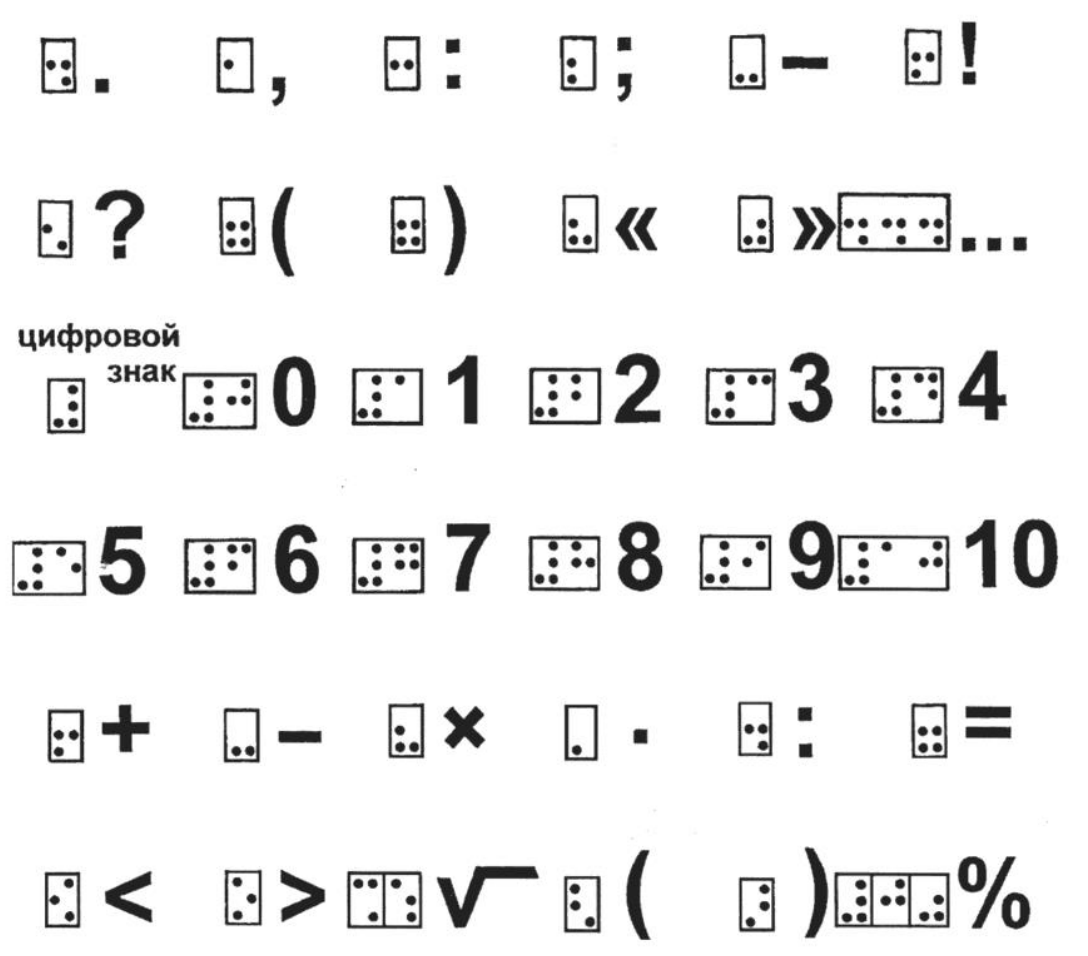

Рис. 9. Небуквенные знаки системы Л. Брайля

На Рисунке 10. приведены примеры записи слов рельефно-точечным шрифтом Л Брайля. 


\section{АРБУЗ \\ ЖЕӞ:
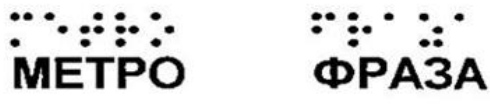

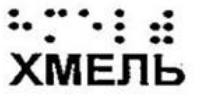 \\ ЦАпัด : \\ ЧАШКА \\ Щ̈:̈:ं: \\ вЫд: : :

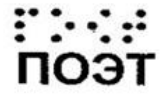 \\ Вь: :: :

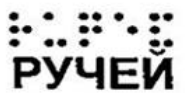

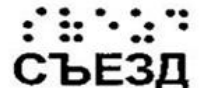

Рис. 10. Примеры записи слов рельефно-точечным шрифтом Л Брайля

Пропедевтическая работа по формированию навыков чтения и письма рельефно-точечным шрифтом Л. Брайля включала выполнение заданий с использованием таких приборов, как «Кубик-буква» и «Брайлевское шеститочие», упражнения на быстрое запоминание знаков брайлевской системы с помощью специальных приемов, предложенных В.3. Денискиной, Т. А. Карандаевой, М.Г. Леушевой.

Анализ итоговых оценок показал, что уровень сформированности навыков чтения и письма рельефно-точечным шрифтом Л. Брайля повысился в обеих группах.

В контрольной группе у 6 студентов навыки чтения сформированы на достаточном уровне у 3 студентов на успешном уровне.

В экспериментальной группе - у 3 студентов на достаточном уровне и у 6 студентов - на успешном уровне.

Уровень сформированности навыков письма стал следующим:

в контрольной группе - у 5 студентов - на достаточном уровне, у 4 студентов - на успешном уровне;

в экспериментальной группе - у 3 студентов - на достаточном уровне, у 6 студентов - на успешном уровне. 
Полученные результаты позволяют сделать вывод о том, что студенты экспериментальной группы достигли более высокого уровня чтения и письма рельефно-точечным шрифтом Л. Брайля, что подтверждает эффективность представленной педагогической технологии.

Количество часов, отпущенное на аудиторные занятия со студентами, не позволяет вместить весь необходимый учебный материал, поэтому некоторые темы выносятся на самостоятельное изучение. Например, тема «Подготовка дошкольников с глубокими нарушениями зрения к чтению и письму по системе Л. Брайля» вынесена на самостоятельное изучение.

Будущие дефектологи должны не только уметь читать и писать по системе Л. Брайля, но и обладать способностью обучать этому детей с нарушениями зрения.

Представленная педагогическая технология обучения чтению и письму по системе Л. Брайля может быть использована родителями детей с глубокими нарушениями зрения, а также педагогами, работающими в системе инклюзивного образования.

\section{Список литературы}

1. Бирючков М.В. Автор великого шеститочия Луи Брайль: Библиографический указатель. - М.: ООО «ИПТК «Логос» ВОС», 2002.

2. Денискина, В.З. Особые образовательные потребности, обусловленные нарушениями зрения и их вторичными последствиями [Текст] / В. 3. Денискина // Дефектология. - 2012. - N 5. - С. 3-13 . - ISSN 0130-3074

3. Карандаева Т. А. Обучение будущих дефектологов чтению и письму по системе брайля: учебное пособие / Мар. гос. ун-т; сост. Т.А. Карандаева. Йошкар-Ола, 2014. - 124 с.

4. Китаева В.С., Карандаева Т.А. Цифровые технологии в образовательном процессе лиц с нарушениями зрения. // Человек в цифровом 
мире: материалы всероссийской (с международным участием) научной конференции студентов и молодых ученых (14-15 мая 2020 г., Йошкар-Ола). Йошкар-Ола: ООО Типография «Вертикаль», 2020. - 174 с. С. 85-89.

5. Костючек Н.С., Денискина В.3. Методические рекомендации по использованию «Прибора прямого чтения» в школах для слепых детей // Дефектология. - 1984. - №1. - С. 77-79.

6. Леушева М. Г., Денискина В. З. Методика ускоренного запоминания основных знаков (букв, цифр, знаков препинания) рельефно-точечной системы Брайля. - М.: ООО «ИПТК «Логос» ВОС», 2006.

7. Потешина М.Б., Рогушин В.К. Обучение чтению и письму по системе Брайля. - М.: ВОС, 1991. - 112 с.

8. Практическое руководство по использованию рельефно-точечного шрифта Л. Брайля при обучении слепых детей. Начальная школа / Сост. В.З. Денискина, Н. П. Шведова. - М.: ООО ИПТК «Логосвос», 2018. - 200 с.

9. Проглядова Г.А. Предупреждение и преодоление трудностей в освоении рельефно-точечного шрифта Брайля слепыми учащимися младших классов: диссертация кандидата педагогических наук: 13.00.03 Москва 2016 http://dlib.rsl.ru

10. Солнцева Л.И., Махортова Г.Х. Брайлевская грамотность слепых в современном обществе // Дефектология. 1994. №2. С. 52-55.18/ Учебнометодическое пособие для изучающих систему рельефно-точечного шрифта Л. Брайля. - М.: ООО «ИПТК «Логос» ВОС», 2005. - Ч. 1.-391 с. 